DOI: $10.15593 / 2224-9826 / 2015.2 .02$

УДК 624.15

\author{
А.Б. Пономарев, М.А. Безгодов, П.А. Безгодов \\ Пермский национальный исследовательский \\ политехнический университет, Пермь, Россия \\ СРАВНЕНИЕ МЕТОДОВ ОПРЕДЕЛЕНИЯ \\ НЕСУЩЕЙ СПОСОБНОСТИ ЗАБИВНЫХ СВАЙ \\ ПО РЕЗУЛЬТАТАМ СТАТИЧЕСКОГО ЗОНДИРОВАНИЯ \\ В СЛАБЫХ ГЛИНИСТЫХ ГРУНТАХ
}

Представлено сравнение отечественных и зарубежных методик расчета несущей способности забивных свай в точках статического зондирования на слабых водонасыщенных глинистых грунтах. В отечественной практике расчеты несущей способности свай производятся по действующим нормативным документам (СП 24.13330.2011 «Свайные фундаменты»). Во многих странах за рубежом расчеты несущей способности свай выполняются по рекомендательным документам. Наиболее распространенными зарубежными методами расчета несущей способности свай в точках статического зондирования являются: метод Шмертманна и Ноттингема, метод де Рейтера и Берингена («Европейский» или «Голландский» метод), метод Бустаманте и Джанзелли (LCPC, или «Французкий метод»), метод Тумай и Факро, метод Айоки и де Аленкара и метод Ислами и Феллениуса. Сопоставление данных методов проведено на примере расчета несущей способности свай в одной из блоксекций строящегося здания в пригороде г. Перми. На данном объекте применялись забивные железобетонные сваи, опирающиеся на слабые глинистые грунты. На площадке были проведены статические и динамические испытания свай, а также выполнено статическое зондирование с использованием зонда 1-го и 2-го типа и пьезозонда с датчиком порового давления.

В результате выполненного сравнения наиболее достоверными методами оказались: метод расчета по СП 24.13330.2011 для зонда 2-го типа, метод Шмертманна и Ноттингема, метод Рейтера и Берингена и метод Ислами и Феллиниуса. Сильное завышение несущей способности свай показал метод расчета по СП 24.13330.2011 для зонда 1-го типа.

Ключевые слова: забивные сваи, слабые глинистые грунты, статическое зондирование, несущая способность свай, натурные испытания свай, динамические испытания, удельное сопротивление грунта по конусу, удельного сопротивления грунта по муфте трения, поровое давление, висячие сваи, пьезоконус.

\author{
A.B. Ponomarev, M.A. Bezgodov, P.A. Bezgodov
}

Perm National Research Polytechnic University, Perm, Russian Federation

\title{
COMPARISON OF METHODS FOR DETERMINATION OF THE BEARING CAPACITY OF DRIVEN PILES USING THE CONE PENETRATION TEST IN SOFT CLAY
}

In the present paper the authors made a comparison of national and foreign methods of calculating the bearing capacity of driven piles in point of the cone penetration test on soft clay soils. In domestic practice calculations bearing capacity of piles made by the current regulations (SP 
24.13330.2011 "Pile foundations"). In In foreign countries, bearing capacity of piles calculations are performed with the recommendation documents. The most common foreign methods of calculating the bearing capacity of piles in point of the cone penetration test include: method Schmertmann and Nottingham, method of deRuiter and Beringen ("European" or "Dutch" method), the method of Bustamante and Gianselli (LCPC or "French method"), method Tumay and Fakhro, method Aoki and De Alencar and method Eslami and Fellenius. A comparison of these methods was carried out on the example of the calculation of the bearing capacity of piles in one block sections building under construction in the suburbs of the city of Perm. At this construction site used driven pile, based on weak clay soils. At the site were carried out pile load test, dynamic tests of piles, and cone penetration test using a cone type 1 , type 2 and piezocones with pore pressure sensor.

A comparison of the most reliable methods were: a method based on SP 24.13330.2011 cone type 2 method Schmertmann and Nottingham, the method of deRuiter and Beringen and method Eslami and Fellenius. Excessively high load-bearing capacity of piles showed the method of calculation for SP 24.13330.2011 probe cone type 1.

Keywords: driven piles, soft clay, cone penetration test, bearing capacity of piles, pile load test, dynamic tests of piles, cone resistance, sleeve friction resistance, pore pressure, friction pile, piezocones.

\section{Введение}

Устройство свайных фундаментов на слабых глинистых грунтах всегда представляет собой решение довольно сложной инженерной задачи. Главная проблема состоит в определении несущей способности свай, при которой обеспечивается не только высокий уровень надежности и безопасности фундамента, но и максимальный уровень экономичности. Одними из наиболее достоверных методов расчета несущей способности свай являются методы статического зондирования, которые широко применяются в отечественной и зарубежной практике.

\section{1. Методики расчета несущей способности свай по результатам статического зондирования}

Расчет по отечественным нормативным документам. Расчет несущей способности свай производится по методике, разработанной еще в 60-е гг. и включенной в СНиП II-17-77. В дальнейшем корректировались лишь переходные коэффициенты, в сторону упрощения расчета [1]. Данная методика приведена в ныне действующем СП 24.13330.2011. Расчет несущей способности свай сводится к определению сопротивления грунта по острию и боковой поверхности сваи по формуле

$$
F_{u}=R_{s} A+f h u,
$$

где $F_{u}$ - частное значение предельного сопротивления забивной сваи; $A-$ площадь острия сваи; $R_{s}$ - предельное сопротивление грунта под нижним концом сваи по данным зондирования в рассматриваемой точке, опреде- 
ляется по формуле (2); $h$ - глубина погружения сваи от поверхности грунта около сваи, м; $u$ - периметр поперечного сечения ствола сваи, м; $f$ - среднее значение предельного сопротивления грунта на боковой поверхности сваи по данным зондирования в рассматриваемой точке, кПа (при применении зонда 1-го типа рассчитывается по формуле (3), при применении зонда 2-го типа - по фомуле (4)).

$$
R_{s}=\beta_{1} q_{s},
$$

где $\beta_{1}$ - коэффициент перехода от $q_{s}$ к $R_{s} ; q_{s}$ - среднее значение сопротивления грунта, кПа, под наконечником зонда, полученное из опыта, на участке, расположенном в пределах одного диаметра выше и четырех диаметров ниже отметки острия проектируемой сваи.

$$
\begin{gathered}
f=\beta_{2} q_{s}, \\
f=\frac{\sum \beta_{i} f_{s i} h_{i}}{h},
\end{gathered}
$$

где $\beta_{2}, \beta_{i}$ - переходные коэффициенты от боковой поверхности зонда к свае; $f_{s}$ - среднее значение сопротивления грунта на боковой поверхности зонда, кПа, определяемое как частное от деления измеренного общего сопротивления грунта на боковой поверхности зонда на площадь его боковой поверхности в пределах от поверхности грунта в точке зондирования до уровня расположения нижнего конца сваи в выбранном несущем слое; $f_{i}$ - среднее сопротивление $i$-го слоя грунта на боковой поверхности зонда, кПа; $h_{i}-$ толщина $i$-го слоя грунта, м.

Одним из существенных отличий СНиП II-17-77 и СП 24.13330.2011 являются значения переходного коэффициента от муфты трения зонда к боковой поверхности сваи $\beta_{i}$. В методике СП 24.13330.2011 не учитывается значение данного коэффициента в зависимости от глубины рассчитываемого слоя.

Расчет несущей способности свай в зарубежнной практике. Во многих странах расчеты несущей способности свай выполняются по рекомендательным документам [1-3]. В общем случае расчет несущей способности свай, как и по отечественным нормам, заключается в определении сопротивления грунта по острию и боковой поверхности сваи по формуле

$$
Q_{u l t}=r_{t} A_{t}+r_{s} A_{s},
$$


где $Q_{u l t}$ - предельная несущая способность сваи, соответствующая предельному сопротивлению сваи $F_{u} ; A_{t}-$ площадь острия сваи; $A_{s}-$ площадь боковой поверхности сваи; $r_{t}$ - сопротивление грунта под острием сваи; $r_{s}$ - сопротивление грунта по боковой поверхности сваи.

Существуют следующие наиболее распространенные методики расчета $[2,3]$ :

1) метод Шмертманна и Ноттингема (Schmertmann and Nottingham);

2) метод де Рейтера и Берингена (deRuiter and Beringen) («Голландский метод» или «Европейский метод»);

3) метод Бустаманте и Джанзелли (Bustamante and Gianselli) (LCPC метод или «Французкий метод»);

4) метод Тумай и Факро (Tumay and Fakhroo);

5) метод Айоки и де Аленкара (Aoki and De Alencar);

6) метод Ислами и Феллениуса (Eslami and Fellenius).

Основное отличие приведенных выше методик заключается в определении сопротивлений грунта под острием сваи $r_{t}$ и по боковой поверхности сваи $r_{s}$.

Метод Шмертманна и Ноттингема (Schmertmann and Nottingham). Данный метод разработан на основе модельных и натурных испытаний свай, проведенных Ноттингемом в 1975 г. и Шмертманном в 1978 г. [2, 3]. Сопротивление грунта под нижним концом сваи (не более $15 \mathrm{MПа)} \mathrm{определяется} \mathrm{по} \mathrm{формуле} \mathrm{(6),} \mathrm{по} \mathrm{боковой} \mathrm{поверхности}$ сваи (не более 120 кПа) - по формуле (7).

$$
r_{t}=C_{q} a
$$

где $C$ - корреляционный коэффициент, зависящий от коэффициента переуплотнения грунта OCR; $q_{c a}-$ усредненное значение удельного сопротивления грунта в зоне влияния.

Определение $q_{c a}$ состоит из пяти шагов:

1. Определяется минимальное из средних значений $q_{c}$ (удельное сопротивление грунта по конусу зонда) в зоне ниже острия сваи на $0,7 D$ или $4 D(D-$ диаметр или сторона сваи).

2. Определяется минимальное значение $q_{c}$ в зонах, приведенных в шаге 1.

3. Определяется среднее значение $q_{c}$, полученное в шаге 1 и 2 .

4. Определяется среднее значение $q_{c}$ в зоне выше острия сваи на 8D по огибающей линии, которая проходит через минимальные значения $q_{c}$. 
5. Определяется среднее значение $q_{c}$, полученное в шаге 3 и 4, которое и берется за $q_{c a}$.

$$
r_{s}=K f_{s},
$$

где $f_{s}$ - удельное сопротивление грунта по муфте трения зонда; $K$ - безразмерный переходный коэффициент, определяемый графическим методом;

Метод де Рейтера и Берингена (de Ruiter and Beringen) («Голландский метод» или «Европейский метод»). Метод был представлен в 1979 г. де Рейтером и Берингеном [2-4]. Сопротивление грунта под нижним концом сваи определяется по формуле (8), по боковой поверхности сваи - по формуле (10).

$$
r_{t}=9 S_{u},
$$

где $S_{u}$ - удельное сопротивление недреннируемому срезу определяется по формуле.

$$
S_{u}=\frac{q_{c a}}{N_{k}},
$$

где $q_{c}$ - удельное сопротивление грунта по конусу зонда; $N_{k}-$ фактор конуса, изменяется в пределах от 15 до 20 (зависит от местных условий), чаще всего принимается равным 20; $q_{c a}$ - усредненное значение удельного сопротивления грунта в зоне влияния (определяется так же, как по методу Шмертманна и Ноттингема);

$$
r_{s}=a S_{u},
$$

где $a$ - коэффициент, принимаемый для нормально уплотненных глин равным 1 , для переуплотненных - 0,$5 ; S_{u}-$ то же, что в формуле (8).

Метод Бустаманте и Джанзелли (Bustamante and Gianselli). Известен также как LCPC-метод (Laboratoire Central des Ponts et Chausees) или «Французкий метод», основан на экспериментальных работах, проведенных Бустаманте и Джанзелли в 1982 г. [2, 3]. Сопротивление грунта под нижним концом сваи определяется по формуле (11), по боковой поверхности сваи - по формуле (12).

$$
r_{t}=k_{b} q_{e q},
$$

где $k_{b}$ - эмпирический коэффициент несущей способности, зависящий от типа грунта и метода устройства сваи; $q_{e q}-$ усредненное значение удельного сопротивления грунта по конусу. 
Усредненное значение удельного сопротивления грунта по конусу $q_{e q}$ находится следующим образом:

1. Определяется среднее значение удельного сопротивления грунта по конусу $\left(q_{c a}\right)$ на участке от $1,5 D$ выше острия сваи до $1,5 D$ ниже острия сваи ( $D$ - диаметр или сторона сваи).

2. Отбрасываются значения удельного сопротивления грунта по конусу $\left(q_{c}\right)$ вне интервала $0,7 q_{c a}<q_{c}<1,3 q_{c a}$.

3. Определяется искомое среднее значение удельного сопротивления грунта по конусу $\left(q_{e q}\right)$ «усеченной» части:

$$
r_{s}=\frac{q_{c}}{k_{c}},
$$

где $q_{c}$ - удельное сопротивление грунта по муфте трения зонда; $k_{c}-$ безразмерный переходный коэффициент, зависящий от типа грунта, типа сваи и метода устройства свай.

Метод Тумай и Факро (Tumay and Fakhroo). Данный метод основан на экспериментальном исследовании глинистых грунтов в Луизиане (США), проведенном Тумай и Факро в 1981 г. [2, 3]. Сопротивление грунта под нижним концом сваи определяется по методу Шмертманна и Ноттингема, а по боковой поверхности сваи - по формуле (13).

$$
r_{s}=m f_{s a}
$$

где $f_{s a}$ - значение удельного сопротивление грунта по муфте трения зонда (для зонда II типа) или среднее значение сопротивления грунта на боковой поверхности зонда (зонд I типа); $m$ - безразмерный переходный коэффициент, определяемый по формуле (14).

$$
m=0,5+9,5 e^{-900 f_{s a}},
$$

где $e=2,718$ - основание натурального логарифма; $f_{s a}$ - то же, что в формуле (13), МПа.

Метод Айоки и де Аленкара (Aoki and De Alencar) [2, 3]. Сопротивление грунта под нижним концом сваи (не более 15 МПа) в данном методе определяется по формуле (15), по боковой поверхности сваи (не более 120 кПа) - по формуле (16).

$$
r_{t}=\frac{q_{c a}}{k_{b}},
$$


где $k_{b}$ - эмпирический коэффициент, зависящий от типа сваи; $q_{c a}-$ усредненное значение удельного сопротивления грунта вокруг острия сваи.

$$
r_{s}=q_{c} \frac{a_{s}}{k_{s}},
$$

где $k_{s}$ - эмпирический коэффициент, зависящий от типа сваи; $q_{c}-$ среднее значение удельного сопротивления грунта по конусу зонда вдоль боковой поверхности сваи; $a_{s}-$ эмпирический коэффициент, зависящий от типа грунта.

Метод Ислами и Феллениус (Eslami and Fellenius). В методе используются данные, полученные при зондировании пьезоконусом (с измерением порового давления) [2, 3, 5]. Сопротивление грунта по конусу переводится в «эффективное» сопротивление грунта по конусу $(q)$ путем вычитания измеренного порового давления из полного удельного сопротивления конуса по грунту. Сопротивление грунта под нижним концом сваи определяется по формуле (17), по боковой поверхности сваи - по формуле (18).

$$
r_{\mathrm{t}}=C_{t} q_{e t}
$$

где $C_{t}-$ корреляционный коэффициент, равный 1 при диаметре или стороне сваи меньше 0,4 м; $q_{e t}-$ среднее значение «эффективного» сопротивления грунта по конусу в зоне влияния.

Зона влияния принимается следующим образом:

1. Если свая проходит слабые грунты и упирается в более прочные, то зона влияния располагается на $8 D$ выше острия сваи и на $4 D$ ниже острия сваи ( $D$ - диаметр или сторона сваи).

2. Если свая проходит прочные грунты и упирается в слабые грунты, то зона влияния располагается на $2 D$ выше острия сваи и на $4 D$ ниже острия сваи ( $D$ - диаметр или сторона сваи).

$$
r_{t}=C_{s} q_{e s}
$$

где $C_{s}-$ корреляционный коэффициент, зависящий от типа грунта; $q_{e s}$ среднее значение «эффективного» сопротивления грунта по конусу вдоль боковой поверхности сваи. 


\section{2. Опытная площадка}

Рассматриваемая площадка находится в пригороде г. Перми. В одной из блок-секций строящегося крупнопанельного здания были проведены статические испытания свай, динамические испытания и испытания грунтов статическим зондированием. На рис. 1 приведена схема мест проведения полевых испытаний.

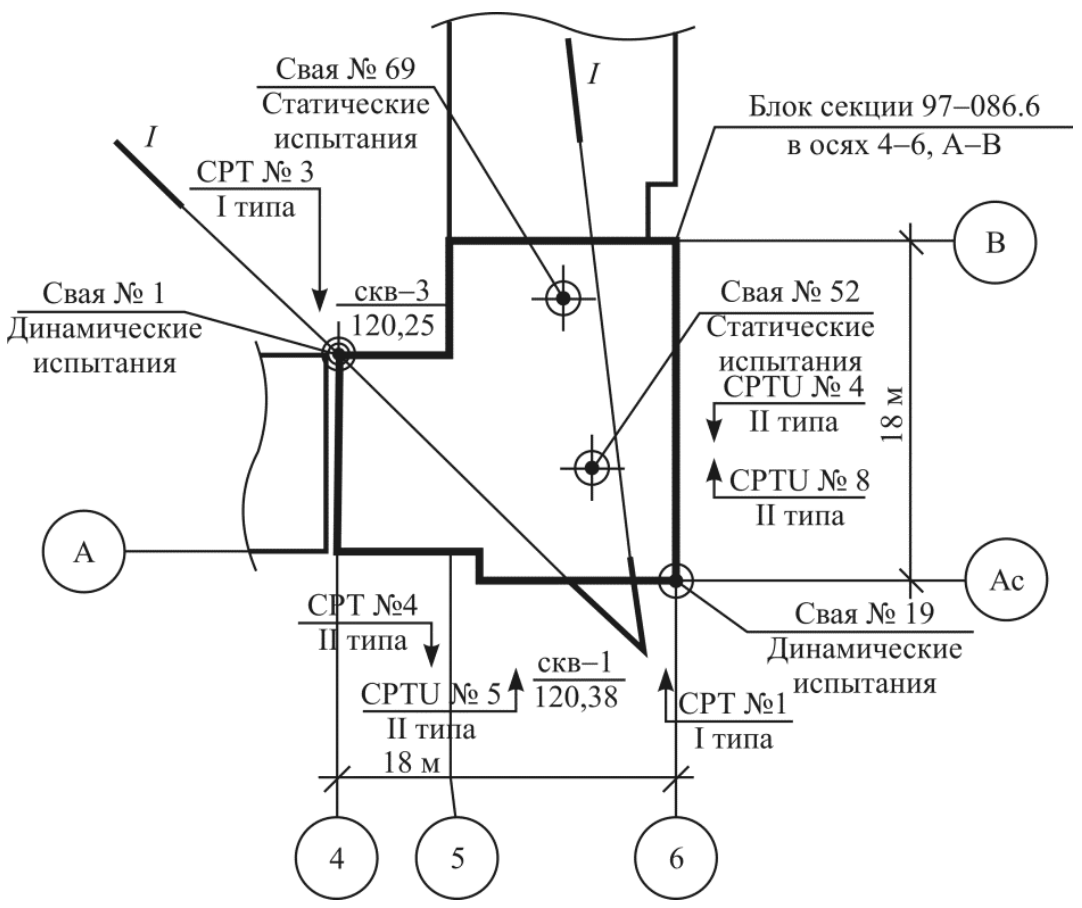

Рис. 1. Схема мест испытания свай статической нагрузкой

(статические испытания), динамической нагрузкой (динамические испытания) и точек статического зондирования (СРТ)

В геологическом строении по данным бурения скважин в пределах исследованных глубин (до 14,0 м) принимают участие аллювиальные отложения современного отдела четвертичной системы (aQIV) (рис. 2).

C поверхности повсеместно залегает почвенно-растительный слой мощностью до 0,1 м. На рассматриваемой площадке блок-секции выделены следующие инженерно-геологические элементы:

ИГЭ-1. Суглинок легкий пылеватый, тяжелый пылеватый, мягкопластичный, редко тугопластичный (aQIV);

ИГЭ-4. Глина легкая пылеватая твердая и полутвердая (aQIV);

ИГЭ-5. Глина легкая пылеватая тугопаластичная (aQIV); 
ИГЭ-6. Глина легкая пылеватая мягкопаластичная (aQIV); ИГЭ-7. Гравийный, галечниковый грунт (aQIV).

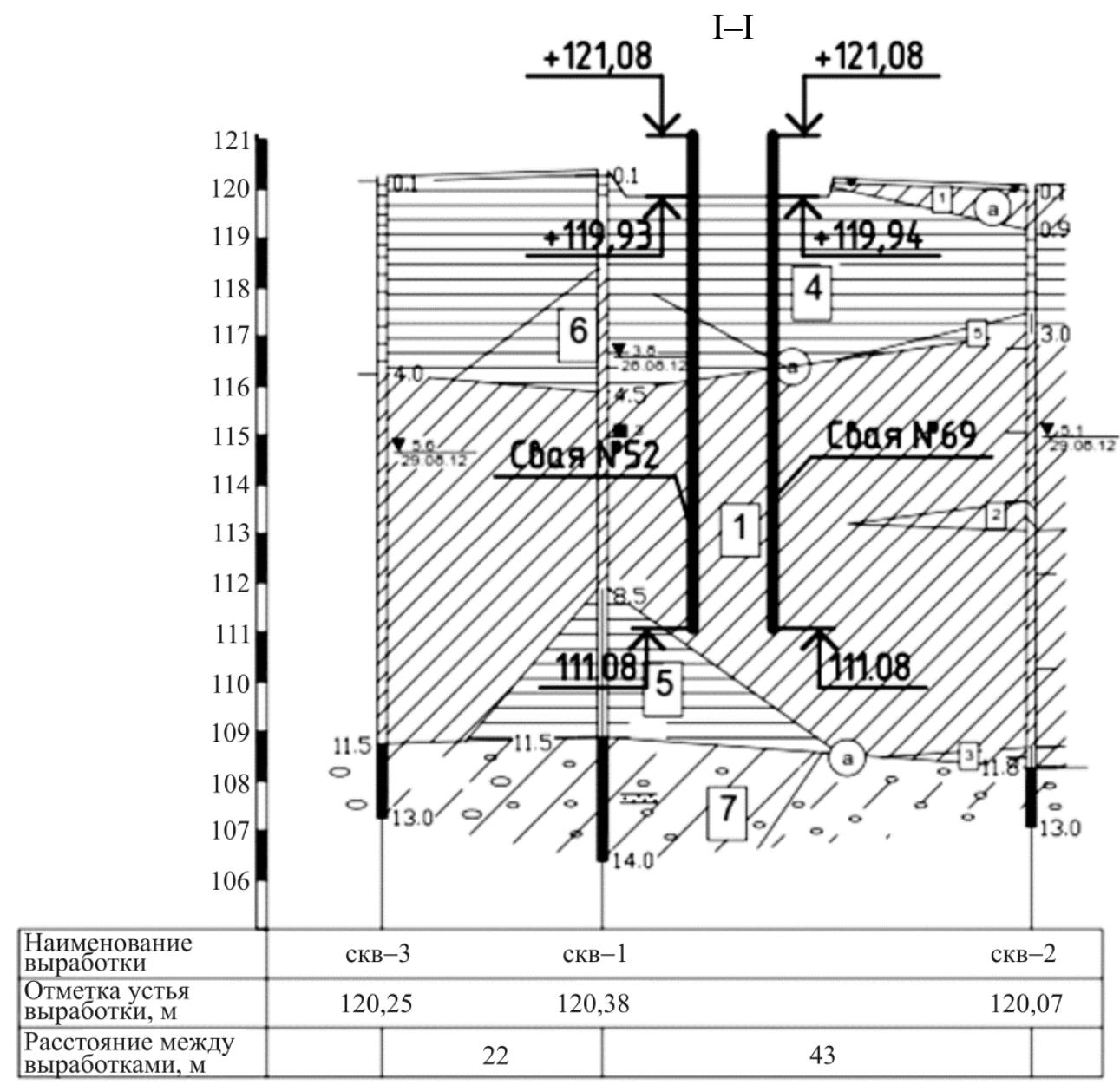

Рис. 2. Инженерно-геологический разрез площадки строительства

В гидрогеологическом отношении (в пределах исследованных глубин до 14,0 м) на момент изысканий (август 2012 г.) подземные воды были вскрыты повсеместно, в суглинках и глинах. Установившийся уровень подземных вод был зафиксирован на глубинах 3,8-5,6 м (отметки в Балтийской системе высот) [6].

Статическое зондирование в точках СРТ № 1 и СРТ № 3 выполнялось в соответствии с ГОСТ 19912-2012 установкой НУСЗ-15 типа С-979 с механической системой задавливания зонда. Тип применяемого зонда - 1. Параметры зонда следующие: диаметр основания конуса 
35,7 мм, угол при вершине конуса $60^{\circ}$, площадь конуса $10 \mathrm{~cm}^{2}$, наружный диаметр штанг 36 мм. Результаты статического зондирования приведены на рис. 3.

Удельное сопротивление грунта под наконечником зонда $q_{c}$, МПа

(-)

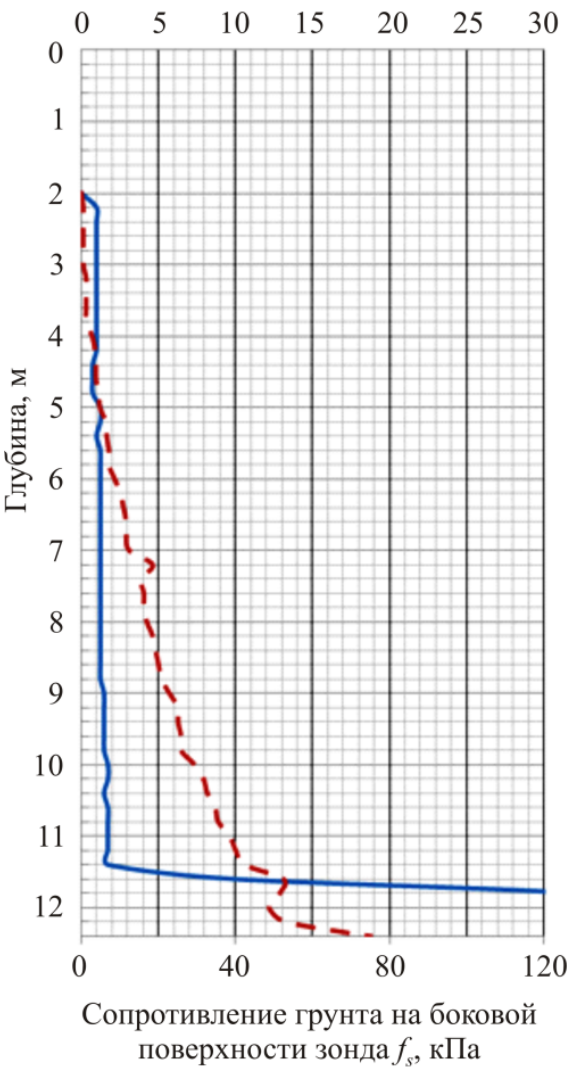

$(--)$
Удельное сопротивление грунта под наконечником зонда $q_{c}$, МПа

(-)

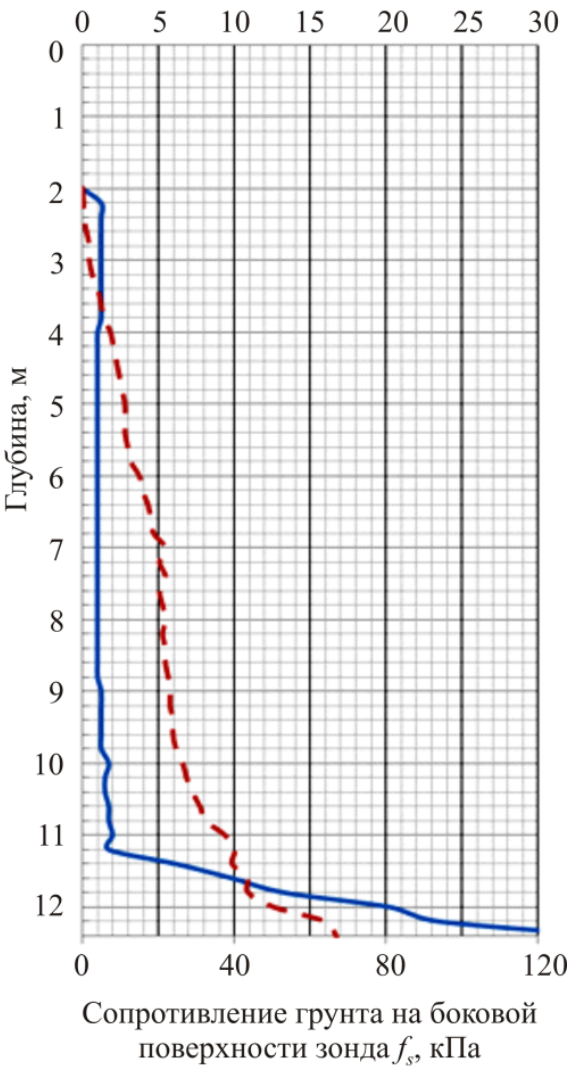

$(--)$

Рис. 3. Графики статического зондирования:

$a$ - точка зондирования СРТ № $1 ; \sigma$ - точка зондирования СРТ № 3

Статическое зондирование в точках СРТ № 4 и СРТU № 4 выполнялось установкой GeoMil LWC100 XS с гидравлической системой задавливания зонда. Зондирование осуществлялось электрическим пьезоконусом с датчиком порового давления и муфтой трения (зонд 2-го типа). Параметры зонда следующие: диаметр основания конуса 35,7 мм, угол при вершине конуса $60^{\circ}$, площадь конуса $10 \mathrm{~cm}^{2}$, площадь муфты трения $150 \mathrm{~cm}^{2}$, наружный диаметр штанг 36 мм, длина штанг 1 м. Результаты статического зондирования приведены на рис. 4. 


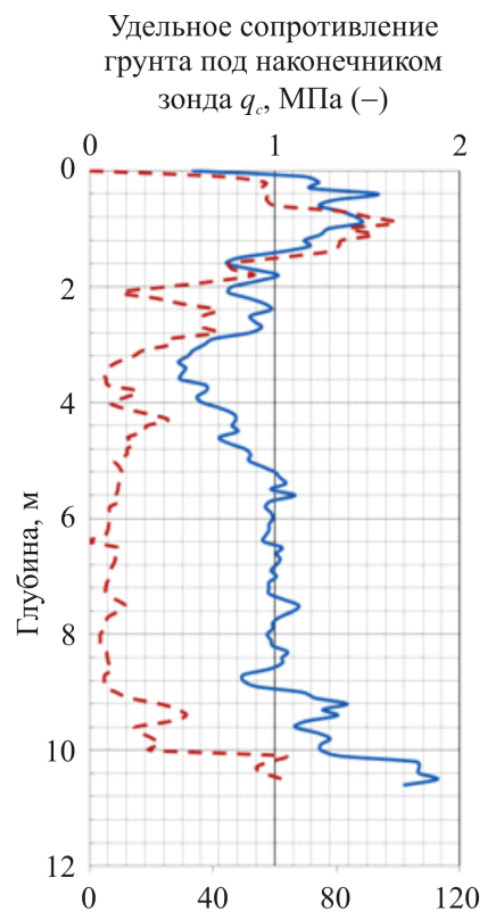

Удельное сопротивление грунта на муфте трения зонда $f_{s}$, кПа $(--)$
Удельное сопротивление грунта под наконечником зонда $q_{c}$, МПа (-)

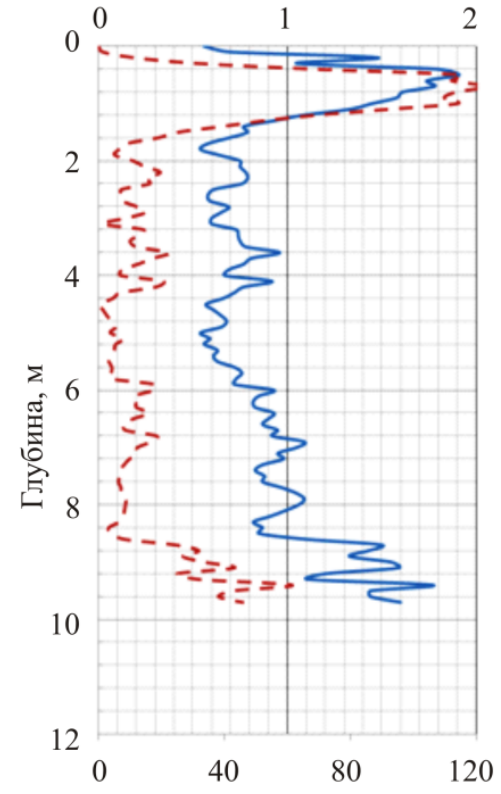

Удельное сопротивление грунта на муфте трения зонда $f_{s}$, кПа

$(--)$
Поровое давление воды, изм. при погр. зонда $u_{2}$, кПа

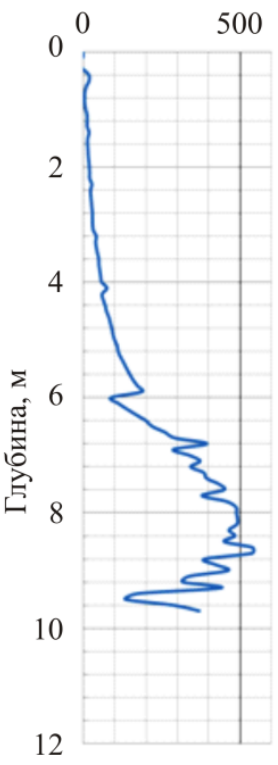

Рис. 4. Графики статического зондирования: $a$ - точка зондирования СРТ № 4; $\sigma$ - точка зондирования CPTU№4 (с измерением порового давления)

Динамические испытания свай проведены в соответствии с требованиями ГОСТ 5686-2012. Забивка свай производилась штанговым дизельным молотом C-330. Параметры молота следующие: общая масса молота 3,5 т, масса ударной части молота 2,5 т, паспортная энергия удара молота 36,7 кДж, масса наголовника 0,1 т. В данной блок-секции было испытано две сваи (свая № 1 и № 19 (см. рис. 1)). Средняя несущая способность свай после «отдыха» 14 дней составила 173,7 кН.

Статические испытания свай проведены в соответствии с требованиями ГОСТ 5686-2012. В качестве нагрузочного устройства использовался гидравлический домкрат с фиксацией каждой ступени нагрузки по манометру [7]. Нагружение испытываемой сваи производилось равномерно, ступенями нагрузки по 40,25 кН (1/10 от 402,5 кН). В данной блок-секции было испытано две сваи (свая № 52 и свая 
№ 69 (см. рис. 1)) длиной 10 м (С100.30-6.1). Несущая способность сваи № 52, испытанной после «отдыха» в течение 20 дней, составила 241,5 кН, сваи № 69, испытанной после «отдыха» в течение 40 дней, 350 кН.

Согласно ГОСТ 5686-2012 продолжительность «отдыха» свай в данных типах грунта составляет 20 сут. В рассмотренных выше методах расчета свай по результатам статического зондирования отсутствует методика учета увеличения несущей способности свай во времени, поэтому для сравнения данных методик за эталонную несущую способность свай рассматриваемой блок-секции принята величина, равная 241,5 кН, соответствующая «отдыху» в течение 20 сут. Вопрос роста несущей способности свай во времени подробно рассмотрен в статьях [8-10].

\section{3. Результаты расчета свай}

Результаты расчета несущей способности свай по приведенным выше методам сведены в таблицу и представлены на рис. 5.

Несущая способность сваи, кН, определенная в точках статического зондирования

\begin{tabular}{|c|c|c|c|c|c|c|c|c|}
\hline \multirow[b]{2}{*}{$\begin{array}{l}\text { Номер точки } \\
\text { статического } \\
\text { зондиования }\end{array}$} & \multicolumn{8}{|c|}{ Метод расчета } \\
\hline & 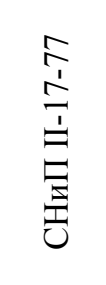 & 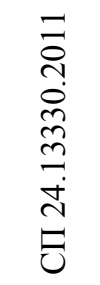 & 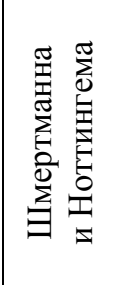 & 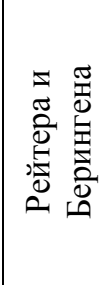 & 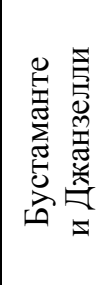 & 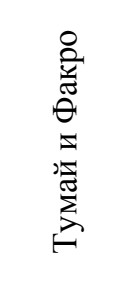 & 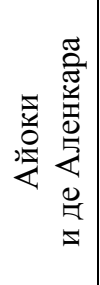 & 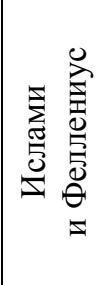 \\
\hline $\begin{array}{l}\text { СРТ № } 4 \\
\text { (зонд 2-го типа) }\end{array}$ & 187 & 272,5 & 260,9 & 292,0 & 158,2 & 181,6 & 180,7 & - \\
\hline $\begin{array}{l}\text { CPTU № } 4 \\
\text { (зонд 2-го типа) }\end{array}$ & 170 & 294,3 & 279,2 & 280,5 & 160,1 & 173,8 & 179,7 & 273,2 \\
\hline $\begin{array}{l}\text { СРТ № } 1 \\
(\text { зонд 1-го типа) }\end{array}$ & 508,9 & 448,7 & - & 298,9 & 166,3 & 216,5 & 187,2 & - \\
\hline $\begin{array}{l}\text { СРТ № } 3 \\
\text { (зонд 1-го типа) }\end{array}$ & 461,3 & 418,6 & - & 268,8 & 147,6 & 191,0 & 162,4 & - \\
\hline Среднее значение & $\frac{178,5^{*}}{485,1}$ & $\frac{283,4^{*}}{433,7}$ & 270,05 & 285,05 & 158,05 & 190,725 & 177,5 & 273,2 \\
\hline
\end{tabular}

* В числителе указано среднее значение несущей способности сваи, вычисленное для зонда 2-го типа, в знаменателе - для зонда 1-го типа. 


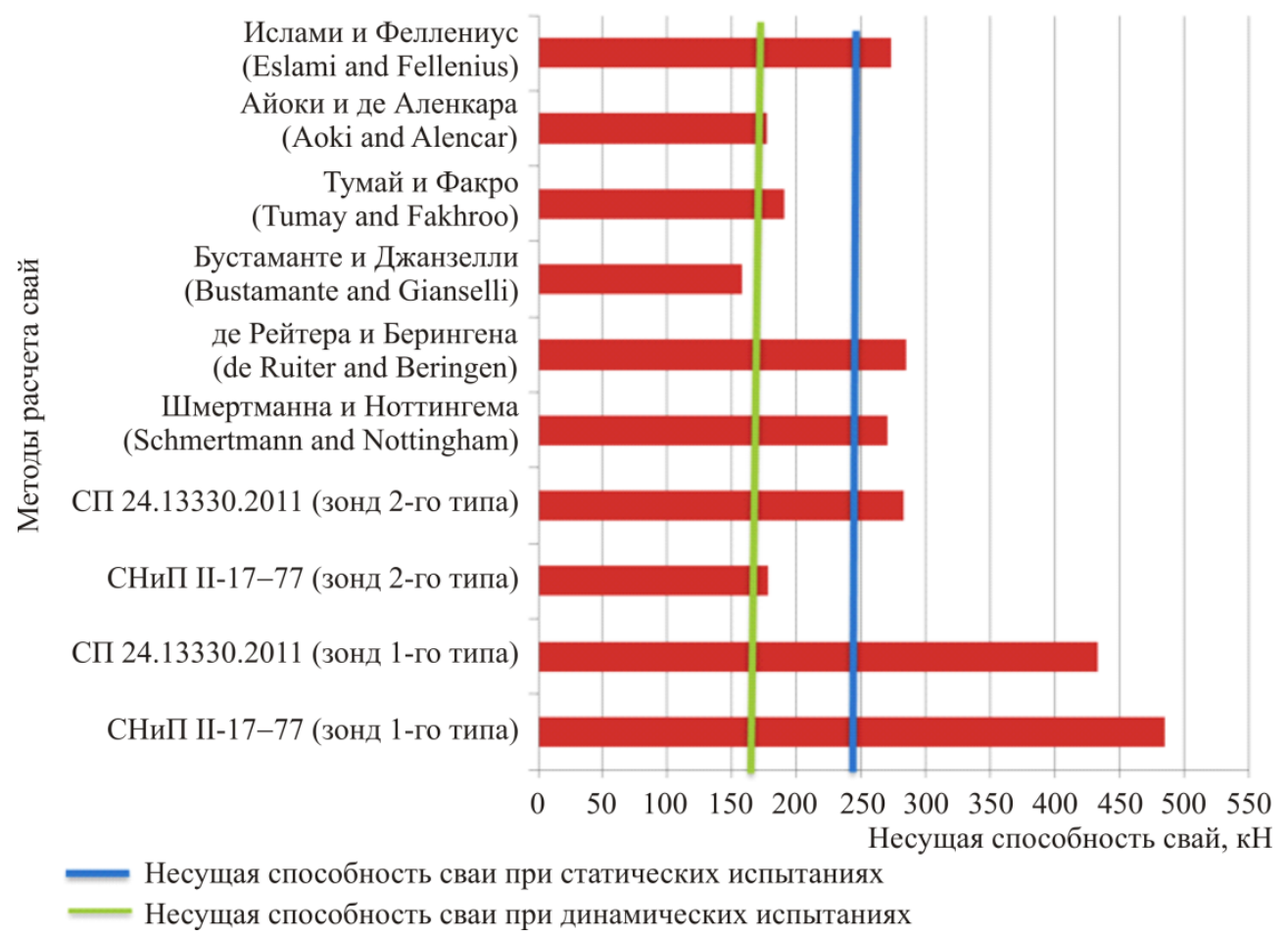

Рис. 5. Гистограмма несущей способности свай, рассчитанной по методу статического зондирования

\section{Выводы}

1. Расчет несущей способности свай по методу СП 24.13330.2011 и СНиП II-17-77 для зонда 1-го типа в слабых глинистых грунтах дает завышение несущей способности свай в среднем в 1,5 раза (относительно статических испытаний свай, проведенных при нормируемом ГОСТ 5686-2012 «отдыхе» в течение 20 сут).

2. Наиболее достоверными среди рассмотренных методов расчета несущей способности свай по результатам статического зондирования в слабых глинистых грунтах (погрешность в пределах $25 \%$ от статических испытаний свай проведенных при нормируемом ГОСТ 56862012 «отдыхе» в течение 20 сут) являются метод расчета по СП 24.13330.2011 для зонда 2-го типа, метод Шмертманна и Ноттингема, метод Рейтера и Берингена и метод Ислами и Феллиниуса. 


\section{Библиографический список}

1. Рыжков И.Б., Исаев О.Н. Статическое зондирование грунтов: моногр. - М.: Изд-во АСВ, 2010. - 496 с.

2. Fellenius H. Basics of Foundation Design. Revised Electronic Edition. - Sidney, Canada, 2014. - 413 p.

3. Salgado R., Lee J. Pile Design Based on Cone Penetration Test Results. - West Lafayette, Indiana, USA, 1999. - 268 p.

4. De Ruiter J., Beringen F.L. Pile foundations for large North Sea structures // Marine Geotechnology. - 1979. - № 3. - P. 267-314.

5. Eslami A., Fellenius B.H. Pile capacity by direct CPT and CPTu methods applied to 102 case histories // Canadian Geotechnical Journal. 1997. - № 6. - P. 886-904.

6. Пономарев А.Б., Татьянников Д.А., Татьянников А.Н. К вопросу проведения инженерно-геологических изысканий на урбанизированных территориях // Вестник Пермского национального исследовательского политехнического университета. Строительство и архитектура. - 2013. - № 2. - С. 74-81.

7. Акбуляков М.А., Сычкина Е.Н., Пономарев А.Б. К вопросу расчета оснований свайных фундаментов, сложенных аргиллитами и песчаниками, с использованием материалов статического зондирования // Вестник Пермского национального исследовательского политехнического университета. Строительство и архитектура. - 2013. - № 1. C. $14-26$.

8. Пономарев А.Б., Безгодов М.А. Несущая способность забивных свай в слабых водонасыщенных грунтах с учетом фактора времени // Вестник Пермского национального исследовательского политехнического университета. Строительство и архитектура. - 2014. - № 1. C. 7-16.

9. Ponomaryov A.B., Zakharov A.V., Bezgodov M.A. Research into time effect influence on pile bearing capacity // Geotechnics of Roads and Railways. - 2014. - Vol. 2. - P. 885-891.

10. Togliani G., Reuter G.R. CPT/CPTu pile capacity prediction methods - question time // 3rd International Symposium on Cone Penetration Testing. - Las Vegas, Nevada, USA, 2014. - P. 993-1002. 


\section{References}

1. Ryzhkov I.B., Isaev O.N. Staticheskoe zondirovanie gruntov [Static probing of soils]. Moscow: Assotsiatsiia stroitel'nykh vuzov, 2010. 496 p.

2. Fellenius H. Basics of Foundation Design. Revised Electronic Edition. Sidney, Canada, 2014. 413 p.

3. Salgado R., Lee J. Pile Design Based on Cone Penetration Test Results. West Lafayette, Indiana, USA, 1999. 268 p.

4. De Ruiter J., Beringen F.L. Pile foundations for large North Sea structures. Marine Geotechnology, 1979, no. 3, pp. 267-314.

5. Eslami A., Fellenius B.H. Pile capacity by direct CPT and CPTu methods applied to 102 case histories. Canadian Geotechnical Journal, 1997, no. 6, pp. 886-904.

6. Ponomarev A.B., Tat'iannikov D.A., Tat'iannikov A.N. K voprosu provedeniia inzhenerno-geologicheskikh izyskanii na urbanizirovannykh territoriiakh [On the engineering geological surveys in urban areas]. Vestnik Permskogo natsional'nogo issledovatel'skogo politekhnicheskogo universiteta. Stroitel'stvo i arhitektura, 2013, no. 2, pp. 74-81.

7. Akbuliakov M.A., Sychkina E.N., Ponomarev A.B. K voprosu rascheta osnovanii svainykh fundamentov, slozhennykh argillitami i peschanikami, s ispol'zovaniem materialov staticheskogo zondirovaniia [To the question of calculation of pile foundation base composed of claystones and sandstones using results of cone penetration tests]. Vestnik Permskogo natsional'nogo issledovatel'skogo politekhnicheskogo universiteta. Stroitel'stvo i arhitektura, 2013, no. 1, pp. 14-26.

8. Ponomarev A.B., Bezgodov M.A. Nesushchaia sposobnost' zabivnykh svai $\mathrm{v}$ slabykh vodonasyshchennykh gruntakh $\mathrm{s}$ uchetom faktora vremeni [The bearing capacity of piles in soft water-saturated clayey soils considering the time factor]. Vestnik Permskogo natsional'nogo isledovatel'skogo politekhnicheskogo universiteta. Stroitel'stvo $i$ arhitektura, 2014, no. 1, pp. 7-16.

9. Ponomaryov A.B., Zakharov A.V., Bezgodov M.A. Research into time effect influence on pile bearing capacity. Geotechnics of Roads and Railways, 2014, vol. 2, pp. 885-891.

10. Togliani G., Reuter G.R. CPT/CPTu pile capacity prediction methods - question time. 3rd International Symposium on Cone Penetration Testing. Las Vegas, Nevada, USA, 2014, pp. 993-1002.

Получено 25.01.2015 


\section{Об авторах}

Пономарев Андрей Будимирович (Пермь, Россия) - доктор технических наук, профессор, зав. кафедрой «Строительное производство и геотехника» Пермского национального исследовательского политехнического университета (614990, г. Пермь, Комсомольский пр., 29, e-mail: andreypab@mail.ru).

Безгодов Михаил Александрович (Пермь, Россия) - аспирант кафедры «Строительное производство и геотехника» Пермского национального исследовательского политехнического университета (614990, г. Пермь, Комсомольский пр., 29, e-mail: m.u.w.a@mail.ru).

Безгодов Петр Александрович (Пермь, Россия) - студент Пермского национального исследовательского политехнического университета (614990, г. Пермь, Комсомольский пр., 29, e-mail: bezgodov.petr@yandex.ru).

\section{About the authors}

Andrei B. Ponomarev (Perm, Russian Federation) - Doctor of Technical Sciences, Professor, Head of Department of Construction Technology and Geotechnics, Perm National Research Polytechnic University (29, Komsomolsky av., Perm, 614990, Russian Federation, e-mail: spstf@pstu.ru).

Mikhail A. Bezgodov (Perm, Russian Federation) - Postgraduate student, Department of Construction Technology and Geotechnics, Perm National Research Polytechnic University (29, Komsomolsky av., Perm, 614990, Russian Federation, e-mail: m.u.w.a@mail.ru).

Pavel A. Bezgodov (Perm, Russian Federation) - Student, Perm National Research Polytechnic University (29, Komsomolsky av., Perm, 614990, Russian Federation, e-mail: bezgodov.petr@yandex.ru). 